\title{
Use of an ultra-clean air flow for surgical field asepsis when performing intravitreous injections in an ambulatory surgical environment
}

\author{
Renata Moreto* ${ }^{*}$, Francyne Veiga Cyrino and Rodrigo Jorge
}

\begin{abstract}
Background: Intravitreal injection of medications is one of the most common procedures performed in ophthalmology. Intravitreal anti-VEGF agents are currently the chosen treatment for ocular fundus diseases, including age-related macular degeneration and diabetic retinopathy. As an invasive procedure it involves risks. The most serious complication from intravitreal injection of anti-VEGF agents is endophthalmitis (EO). Although rare, EO can result in devastating loss of vision. This article evaluates whether the use of an ultra-clean air flow (UA) can be another useful tool in the prevention of EOs. Accordingly, the maintenance of asepsis of the surgical field of intravitreal injections was verified with and without the use of UA.
\end{abstract}

Methods: The study was conducted in operating room of an ambulatory surgery center on four different surgical days when just intravitreal injections were scheduled. Two experiments using two Blood Agar and two Chocolate Agar plates (first 2 days; 4 plates by day) were carried out by positioning an UA directed to the surgical table and two other experiments (last 2 days; 4 plates per day) were carried out using similar plates without the use of the UA. All Blood Agar and four Chocolate Agar plates were positioned on the surgical table, close to the surgical filed. At the end of the day, after the conclusion of the intravitreous injections, the plates were sent for a biomolecular study that was carried out after 1 day of incubation at $37^{\circ} \mathrm{C}$.

Results: The sixteen plates, eight Blood Agar and eight Chocolate Agar, were analyzed qualitatively for the growth or not of microorganism's colonies and identification of their species. The biomolecular study demonstrated the growth of bacteria of the genus Micrococcus sp. with the use of the UA and without the the UA bacterias of the genera Bacillus sp, Staphylococcus haemolyticus, Staphylococcus aureus and Staphylococcus cohnii ssp urealyticus were found.

Conclusion: The use of UA close to the operating table prevented the growth of pathogenic bacteria and should be considered as an alternative tool to avoid the contamination of materials and drugs used for intravitreal injections.

Keywords: Endophthalmitis, Surgical infection, Intravitreous injections, Asepsis techniques, Ultra-clean air flow

${ }^{*}$ Correspondence: remoreto@yahoo.com.br

Ophthalmology, Ribeirão Preto Medical School, University of São Paulo,

Avenida Bandeirantes, 3900, Ribeirão Preto, SP 14049-990, Brazil

\section{Background}

The development of targeted molecular therapy to inhibit vascular endothelial growth factor (VEGF) has revolutionized the treatment and visual prognosis of retinal diseases such as diabetic retinopathy and age-related macular degeneration, as well as macular edema and retinal vein occlusion through performing intravitreal

(c) The Author(s) 2020. This article is licensed under a Creative Commons Attribution 4.0 International License, which permits use, sharing, adaptation, distribution and reproduction in any medium or format, as long as you give appropriate credit to the original author(s) and the source, provide a link to the Creative Commons licence, and indicate if changes were made. The images or other third party material in this article are included in the article's Creative Commons licence, unless indicated otherwise in a credit line to the material. If material is not included in the article's Creative Commons licence and your intended use is not permitted by statutory regulation or exceeds the permitted use, you will need to obtain permission directly from the copyright holder. To view a copy of this licence, visit http://creativeco mmons.org/licenses/by/4.0/. The Creative Commons Public Domain Dedication waiver (http://creativecommons.org/publicdomain/ zero/1.0/) applies to the data made available in this article, unless otherwise stated in a credit line to the data. 
injections (IVIs) of these drugs [1, 2]. As an invasive procedure it involves risks. The most serious complication from IVIs of anti-VEGF agents is endophthalmitis (EO). Despite the incidence of EO after anti-VEGF IVI is very low $(0.038$ to $0.065 \%)[3,4]$, it may result in partial visual loss or even blindness [5, 6].

Etiological agents that usually cause EO are fairly abundant in the conjunctival flora of the normal human eye. The most usual ones are coagulase-negative staphylococci (CONS), most commonly Staphylococcus epidermidis followed by Streptococcus viridans, which is especially related to contamination of the operating room when there is frequent conversation during the IVIs procedures [7]. Staphylococcus aureus, Bacillus spss and Pseudomonas spss are also important microorganisms to be considered in the etiology of EO $[2,8]$.

In Canada and in USA, IVIs are mainly performed in the office [9], whereas in other countries IVI are limited to the operation rooms (OR) or to a sterile room with hygienic standards in order to decrease the risk of infection and EO. Important hygienic practices include hand hygiene, appropriate OR clothing, face masks for physicians and staff assisting in IVIs, the use of sterilized surgical fields, and isolation of the eyelashes and topical administration of $5 \%$ povidone-iodine $30 \mathrm{~s}$ before IVIs [9-11]. In addition, methods that may improve the quality of the OR air, such as ultraclean room ventilation, should be considered $[13,15]$. In this context, in the present study, we evaluated the use of a new ultra-clean air flow (UA) as a possible tool to prevent contamination of the operating table. The ultra-clean airflow was obtained by means of a mobile air filter (Operio Mobile ${ }^{\circledR}$, Toul Meditech), which produces a directed, non-turbulent ultra-clean airflow over the sterile instruments. The airflow speed is $0.4-0.5 \mathrm{~m} / \mathrm{s}$ and has a capacity to clean the air of $400 \mathrm{~m}^{3} / \mathrm{h}$ and a protection area up to $120 \mathrm{~cm}$. This system uses a HEPA filter that eliminates particles smaller than $0.3 \mu \mathrm{m}$ from the air [14], and, consequently, may contribute to avoid contamination of the surgical filed and EO.

\section{Methodology}

The study was conducted in the OR of the Ophthalmology sector at Hospital das Clínicas of the University Hospital, School of Medicine of Ribeirão Preto, University of São Paulo, a tertiary health care hospital.

The study was carried out on four different surgical days. The analyzes were performed as follows: the surgical tables were always positioned in the same place. On each day of IVIs, two Blood Agar and two Chocolate Agar were placed in the same location, at a distance of $120 \mathrm{~cm}$ from the site where the UA system would be located and in the same place without the UA. Two days, 11/29/2018 and $12 / 6 / 2018$ with the UA directed to the operating table. Two days, $12 / 12 / 2018$ and $12 / 19 / 2018$, without the use of the UA. A total of 16 culture plates were used. In total 99 IVIs were done with the UA and 102 without it.

The UA was obtained by means of a mobile air filter (Operio Mobile ${ }^{\circledR}$, Toul Meditech) which produces a directed, non-turbulent ultra-clean airflow over the sterile instruments. According to the manufacturer's specifications, this system uses a HEPA filter that eliminates particles smaller than $0.3 \mu \mathrm{m}$ from the air. The air flow speed is $0.4-0.5 \mathrm{~m} / \mathrm{s}$, with a capacity to clean the air of $400 \mathrm{~m}^{3} / \mathrm{h}$ and a protection area of up to $120 \mathrm{~cm}$ (Figs. 1 and 2).

The culture plates were covered while still on the surgical field and promptly taken to the Microbiology Laboratory of the University Hospital, School of Medicine of Ribeirão Preto. After $24 \mathrm{~h}$ of incubation at $37{ }^{\circ} \mathrm{C}$, the plates were subjected to a biomolecular study of microorganisms in BioMerieux ${ }^{\circledR}$ equipment. This equipment identifies which species of microorganism grew on blood Agar and chocolate Agar.

\section{Results}

All culture plates showed microorganism growth, which are described in Table 1.

The biomolecular analysis of the culture plates positioned on the surgical tables during use of the UA revealed the growth of bacteria of the genus Micrococcus sspp with a 95\% probability of success (Table 1, Fig. 3).

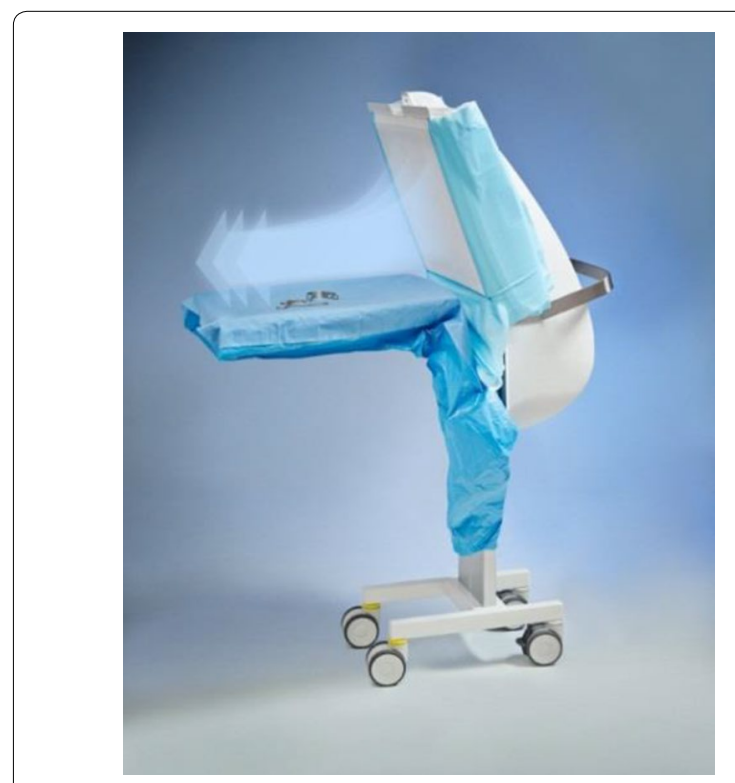

Fig. 1 Operio Mobile ${ }^{\circledR}$ equipment with a HEPA filter. The arrows represent the direction of the airflow. Image obtained from www. toulmeditech.com/en/products/6 at 30/03/2019) 


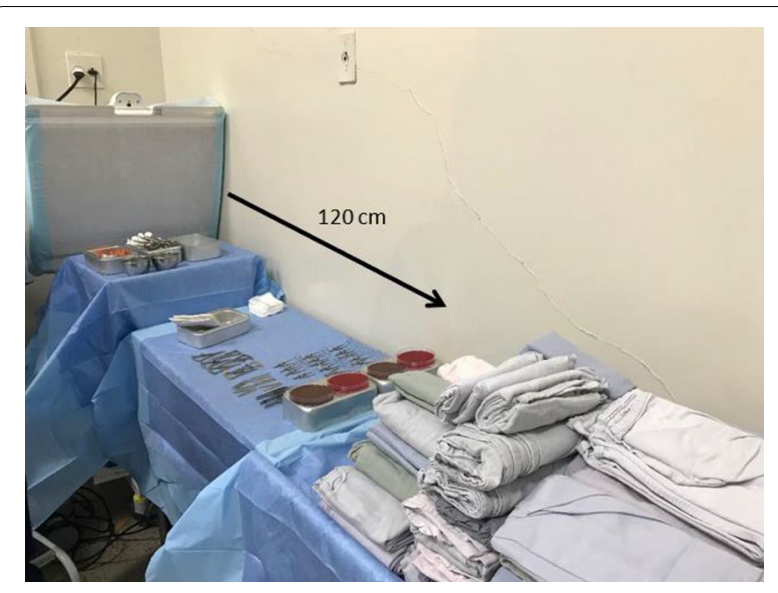

Fig. 2 Surgical field with ultra-clean airflow directed towards the surgical table and towards culture plates positioned at a distance of $120 \mathrm{~cm}$ from the flow outlet

Table 1 Microorganisms identified in culture medium positioned on the surgical table of intravitreous injections at the University Hospital, Faculty of Medicine of Ribeirão Preto with and without receiving ultraclean airflow directed at the surgical field

\begin{tabular}{ll}
\hline $\begin{array}{l}\text { Microorganism identified } \\
\text { in culture medium positioned } \\
\text { on the surgical field } \\
\text { and receiving ultraclean airflow }\end{array}$ & $\begin{array}{l}\text { Microorganisms identified } \\
\text { in culture medium positioned } \\
\text { on the surgical field } \\
\text { without receiving ultraclean } \\
\text { airflow }\end{array}$ \\
\hline Micrococcus sp & $\begin{array}{l}\text { Staphylococcus haemolyticus } \\
\text { Staphylococcus aureus } \\
\text { Staphylococcus cohnii ssp urealyticus } \\
\text { Bacillus sp }\end{array}$ \\
\end{tabular}

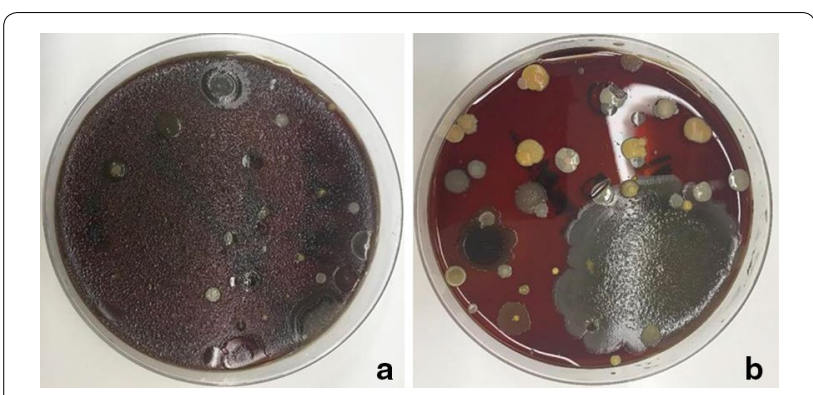

Fig. 3 Images of culture medium plates provided by the Microbiology Laboratory of HCFMRP-USP after incubation at $37^{\circ} \mathrm{C}$ for $24 \mathrm{~h}$. Plate a blood agar, was positioned on the surgical table with ultraclean airflow directed at it. Plate $\mathbf{b}$ was positioned on the surgical table without receiving an ultraclean airflow

The biomolecular analysis of the culture plates positioned on the surgical tables without the use of the UA revealed the growth of bacteria of the genus Bacillus sspp with a $97 \%$ probability of success, as well as the growth of the following other species, with their respective probabilities of success: Staphylococcus haemolyticus (99\%), Staphylococcus aureus (98\%) and Staphylococcus cohnii ssp urealyticus (96\%). (Table 1, Fig. 3).

In all four IVIs days, there were no cases of EO, with or without the use of UA.

\section{Discussion}

Antisepsis with iodine-povidone, eyelid retraction with speculum, use of face masks to prevent the spread of droplets by the medical team and patient and reduced speech in OR, are recommended measures that may contribute to the reduction in EO after IVIs [7, 10]. On the other hand, there are studies suggesting that intravitreal injections may be performed in the office setting with iodine-povidone and sterile tip technique only, without the use of sterile gloves and sterile drapes [9]. Despite the controversy of more or less rigorous measures to prevent EO, the present study adds additional information on a new tool that maybe used during intravitreal injections either in the operating room, or in the office setting.

One of the reasons to recommend the performance of IVIs in a surgical environment and not in the office, is the OR air quality and the theory that air borne particles may cause infection. The first report of the efficacy of UA in reducing the rates of surgical infection was in orthopedic implant surgery [15]. In ocular surgeries, ESCRS conducted a post-phacoemulsification EO study comparing minimum airflow, air changes per hour and UA systems using horizontal or vertical laminar airflow systems with no clear results [16]. However, in another study that simulates the IVIs environment, the unidirectional air flow showed protection for both the instrument table and the ocular surface, showing that UA can therefore prevent sufficiently infections in the context of IVIs [17].

From our samples of microorganisms that showed growth in the culture plates, we observed that in the presence of UA, there was growth of Micrococcus sspp, a Gram-positive bacteria 0.3 to $3.5 \mu \mathrm{m}$ in diameter, usually present in the normal flora of the skin, mucosa and oropharynx, and far known to have no virulence mechanisms [18].

Among the microorganisms deposited on the culture plates in the surgical field without the UA, S. cohnii, S. haemolyticus (both bacteria of the CONS group) and $S$. aureus are known to be etiological agents of $\mathrm{OE}$ after intraocular procedures. In addition, S. cohnii is related to rare cases of endocarditis, pneumonias, urinary tract infections, brain abscesses, and septic arthritis, among another infections [18-20]. When isolated from human infections, S. cohnii shows a multiresistant profile. Finally, S. haemolyticus is the second species most frequently isolated species from human blood cultures and is highly resistant to antimicrobial agents [20]. 
As for the strain of Bacillus sspp that grew, also in the absence of UA, the majority is non-pathogenic, but for a complete analysis of the identified bacillus it would be necessary to apply the BAAR method, in order to rule out the possibility of being a pathogenic agent such as B. tuberculosis [18].

Regarding the maintenance of asepsis of the surgical field, the literature has emphasized the importance of maintaining it throughout the surgical period $[10,12$, 13].

The data presented in this work reveal that the use of UA directed to the surgical field can be a useful auxiliary tool in an attempt to ensure the maintenance of asepsis of instruments and needles to be used in IVIs, as well as ensuring asepsis during manipulation (aspiration of the medications) of IVIs.

Our work has some limitations. The number of colonies for each isolated microorganism was not verified, and for this reason there was just a qualitative analysis, instead of a quantitative analysis with statistics. In addition, due to the reduced physical space, the UA was not placed so its effect would extend over the ocular surface, which is the objective of our next study. Finally, there was not a control group with a device providing airflow that was not "ultraclean", to check if the absence of pathogenic bacteria growth may be due to rapid air flow and not the HEPA filtered air.

The use of UA close to the operating table prevented the growth of pathogenic bacteria and should be considered as an alternative tool to avoid the contamination of materials and drugs used for intravitreal injections.

\section{Acknowledgements}

To the Fellows Leandro Jerez Chaves, Julian Cássio, Tomás Teixeira Pinto and Amanda Schnorr who contributed to the intravitreal injections.

To the nursing team that participated in the performance of intravitreal injections.

\section{Authors' contributions}

All authors have made substantial contributions to the conception and design of the work; RM has done the acquisition, analysis, interpretation, literature review and paper writing. FVC and RJ: analysis, paper review. All authors read and approved the final manuscript.

\section{Funding}

There was no funding for the research reported.

\section{Availability of data and materials}

All data generated or analysed during this study are included in this published article [and its supplementary information files].

Ethics approval and consent to participate

Not applicable. Our manuscript does not report nor involve the use of any animal or human data or tissue.

\section{Consent for publication}

Not applicable.

\section{Conflict of interests}

The authors declare that they have no conflict of interests.
Received: 15 May 2020 Accepted: 5 November 2020

Published online: 19 November 2020

\section{References}

1. Sachdeva MM, Moshiri A, Leder HA, Scott AW. Endophthalmitis following intravitreal injection of anti-VEGF agents: long-term outcomes and the identification of unusual micro-organisms. Ophthalmic Inflamm Infect. 2016:6:2 (Published online 2016 Jan 12)

2. Labardini CP, Blumenthal EZ. Causative pathogens in endophthalmitis after intravitreal injection of anti-vascular endothelial growth factor agents. Rambam Maimonides Med J. 2018;9(4):1-6 (published online ahead of print, 2018 Sep 2).

3. McCannell CA. Meta-analysis of endophthalmitis after intravitreal injection of anti-vascular endothelial growth factor agents: causative organisms and possible prevention strategies. Retina. 2011;31:654-61.

4. Hadayer A, Zahavi A, Livny E, et al. Patients wearing face masks during intravitreal injections may be at a higher risk of endophthalmitis. Retina. 2020:40(9):1651-6.

5. Jackson TL, Eykyn SJ, Graham EM, Stanford MR. Endogenous bacterial endophthalmitis: a 17-year prospective series and review of 267 reported cases. SurvOphthalmol. 2003;48(4):403-23.

6. Callegan MC, Engelbert M, Parke DW 2nd, Jett BD, Gilmore MS. Bacterial endophthalmitis: epidemiology, therapeutics, and bacterium-host interactions. ClinMicrobiol Rev. 2002;15(1):111-24.

7. Nentwich MM, Yactayo-Miranda Y, Schwarzbach F, Wolf A, Kampik A, Mino de Kaspar $\mathrm{H}$. Endophthalmitis after intravitreal injection: decreasing incidence and clinical outcome-8-year results from a tertiary ophthalmic referral center. Retina. 2014;34:943-50.

8. Kumar A, Sundar DM, Mutha V. Commentary: the changing scenario of cluster endophthalmitis. Indian J Ophthalmol. 2018;66(8):1079.

9. Meyers L, Almeida D, Abràmoff MD: Intravitreal injection technique. https ://webeye.ophth.uiowa.edu/eyeforum/tutorials/intravitreal-injection/ index.htm. Accessed Sept 2020.

10. Grzybowski A, Told R, Sacu S, et al. 2018 Update on intravitreal injections: Euretina Expert Consensus Recommendations. Ophthalmologica. 2018;239(4):181-93

11. Barroso LF, Cazella SP, Nepomuceno AB, Toscano L, Castilho LAS, Furlan EMR, Messias A, Scott IU, Jorge R. Comparative efficacy of two different topical povidone-iodine $5 \%$ regimens in reducing conjunctival bacterial flora: a randomized parallel double-masked clinical trial. PLOS ONE. 2017;12(12):e0189206.

12. Iwamoto P. Aseptic Technique. In: APIC Text of Infection Control and Epidemiology. Association for Professionals in Infection Control and Epidemiology, Inc. 2013; chapter 20. http://text.apic.org/item-21/chapt er-20-aseptic-technique.

13. Brasil. Agência Nacional de Vigilância Sanitária. Medidas de Prevenção de Endoftalmites e de Síndrome Tóxica do Segmento Anterior Relacionadas a Procedimentos Oftalmológicos Invasivos/Agência Nacional de Vigilância Sanitária. Brasília: Anvisa, 2017.

14. https://www.toulmeditech.com/docs/Datablad_Operio_Mobile_EN.pdf Accessed Sep 2020

15. Friberg BE, Friberg S, Burman LG. Zoned vertical ultraclean operating room ventilation. A novel concept making long side walls unnecessary. Acta Orthop Scand. 1996;67:578-82.

16. Barry P, Cordovés L, Gardner S (The European Society for Cataract and Refractive Surgeons, Temple House, Temple Road, Blackrock, Co Dublin, Ireland). ESCRS Guidelines for Prevention and Treatment of Endophthalmitis Following Cataract Surgery: Data, Dilemmas and Conclusions 2013; 2018. www.escrs.org/endophthalmitis/guidelines/ENGLISH_2018_updat ed.pdf Accessed Sep 2020.

17. Lapid-Gortzak R, Traversari R, van der Linden JW, Lesnik Oberstein SY, Lapid O, Schlingemann RO. Mobile ultra-clean unidirectional airflow screen reduces air contamination in a simulated setting for intra-vitreal injection. Int Ophthalmol. 2017;37(1):131-7.

18. Kloos WE. Bannerman TL Staphylococcus and Micrococcus. In: Murray P, Baron E, Pfaller M, Tenover F, Yolken R, editors. Manual of clinical microbiology. Washington: American Society for Microbiology; 1999. p. 264-82. 
19. Drozenova J, Petras P. Characteristics of coagulase-negative staphylococci isolated from hemocultures. Epidemiol Mikrobiol Imunol. 2000:49:51-8.

20. Kloos WE, Bannerman TL. Update on clinical significance of coagulasenegative staphylococci. Clin Microbiol Rev. 1994;7:117-40.

\section{Publisher's Note}

Springer Nature remains neutral with regard to jurisdictional claims in published maps and institutional affiliations.
Ready to submit your research? Choose BMC and benefit from:

- fast convenient online submission

- thorough peer review by experienced researchers in your field

- rapid publication on acceptance

- support for research data, including large and complex data types

- gold Open Access which fosters wider collaboration and increased citations

- maximum visibility for your research: over 100M website views per year

At BMC, research is always in progress.

Learn more biomedcentral.com/submissions 